\title{
A case of asymptomatic SARS-CoV-2 infection followed by secondary community acquired pneumonia
}

\author{
Jiaxiang Chen ${ }^{1,2 \#}$, Chong Tian ${ }^{2 \#}$, Xinge Cheng ${ }^{3}$, Rongpin Wang ${ }^{2}$, Hourong Zhou ${ }^{2,4}$, Xianchun Zeng ${ }^{2}$ \\ ${ }^{1}$ Guizhou University School of Medicine, Guiyang, China; ${ }^{2}$ Department of Medical Imaging, Guizhou Provincial People's Hospital, Guiyang, China; \\ ${ }^{3}$ Department of Graduate School, Zunyi Medical University, Zunyi, China; ${ }^{4}$ Department of Research and Education, Jiangjunshan Hospital of \\ Guizhou Province, Guiyang, China \\ "These authors contributed equally to this work. \\ Correspondence to: Xianchun Zeng, MD. Department of Medical Imaging, Guizhou Provincial People's Hospital, No. 83, East Zhongshan Road, \\ Guiyang, China. Email: zengxianchun04@foxmail.com.
}

Submitted Jul 09, 2020. Accepted for publication Aug 06, 2020.

doi: 10.21037/qims-20-847

View this article at: http://dx.doi.org/10.21037/qims-20-847

\section{Introduction}

The outbreak of coronavirus disease 2019 (COVID-19) caused by a novel coronavirus (SARS-CoV-2) in December 2019 has spread globally. The SARS-CoV-2, which is mainly transmitted through droplets (1), has infected millions of people worldwide and caused hundreds of thousands of deaths. On January 30, 2020, the World Health Organization (WHO) declared the outbreak a Public Health Emergency of International Concern. Some patients with SARS-CoV-2 infection are clinically asymptomatic; and they are more likely to relatively young and healthy (2). There has been no report of secondary infection to asymptomatic COVID-19. Here, we report an asymptomatic COVID-19 case who developed secondary community-acquired pneumonia (CAP) during convalescence.

\section{Case presentation}

A 29-year-old man with no clinical symptoms was admitted to Jiangjunshan Hospital due to positive results of nasopharyngeal swab real-time reverse transcription polymerase chain reaction (RT-PCR) test for SARS-CoV-2 on February 19, 2020. The patient was on the same flight as a confirmed COVID-19 case on January 23, 2020, and his daughter who flew from Wuhan to Guiyang on January 16, 2020 was tested positive for SARS-CoV-2 RNA.
Chest computed tomography (CT) plain scan showed no obvious pulmonary abnormality, so he was diagnosed with asymptomatic SARS-CoV-2 infection and subsequently given Lopinavir/Ritonavir, Abidol combined with interferon inhalation for antiviral treatment, and Thymalfasin for immunopotentiation. During treatment, the patient's vital signs remained normal. On day 18 of hospitalization, two pharyngeal swab RT-PCR tests performed at an interval $>24$ h both showed negative result for SARS-CoV-2 . Follow-up CT showed no significant pulmonary changes; and laboratory tests evaluating hepatic and renal function, cardiac function, electrolytes and coagulation function showed no abnormalities. Thus, the patient was discharged.

During medical observation, no clinical symptoms appeared and the vital signs remained normal. Serum antibody tests for SARS-CoV-2 IgG and IgM both showed positive results, and multiple stool and pharyngeal swab RTPCR tests consistently showed negative results. However, follow-up chest CT showed infection in the upper lobe of the right lung on day 27 of isolation (Figure 1A), and the lesions progressed on day 32 (Figure 1B). Thus, the patient was removed from medical observation and admitted again.

Laboratory tests showed normal leukocyte count $\left(4.78 \times 10^{9} / \mathrm{L}\right)$, normal neutrophil count $\left(2.25 \times 10^{9} / \mathrm{L}\right)$, normal lymphocyte count $\left(1.88 \times 10^{9} / \mathrm{L}\right)$, increased eosinophils (5.20\%) and normal hypersensitive C-reactive protein (HsCRP). The patient was finally diagnosed with CAP based 

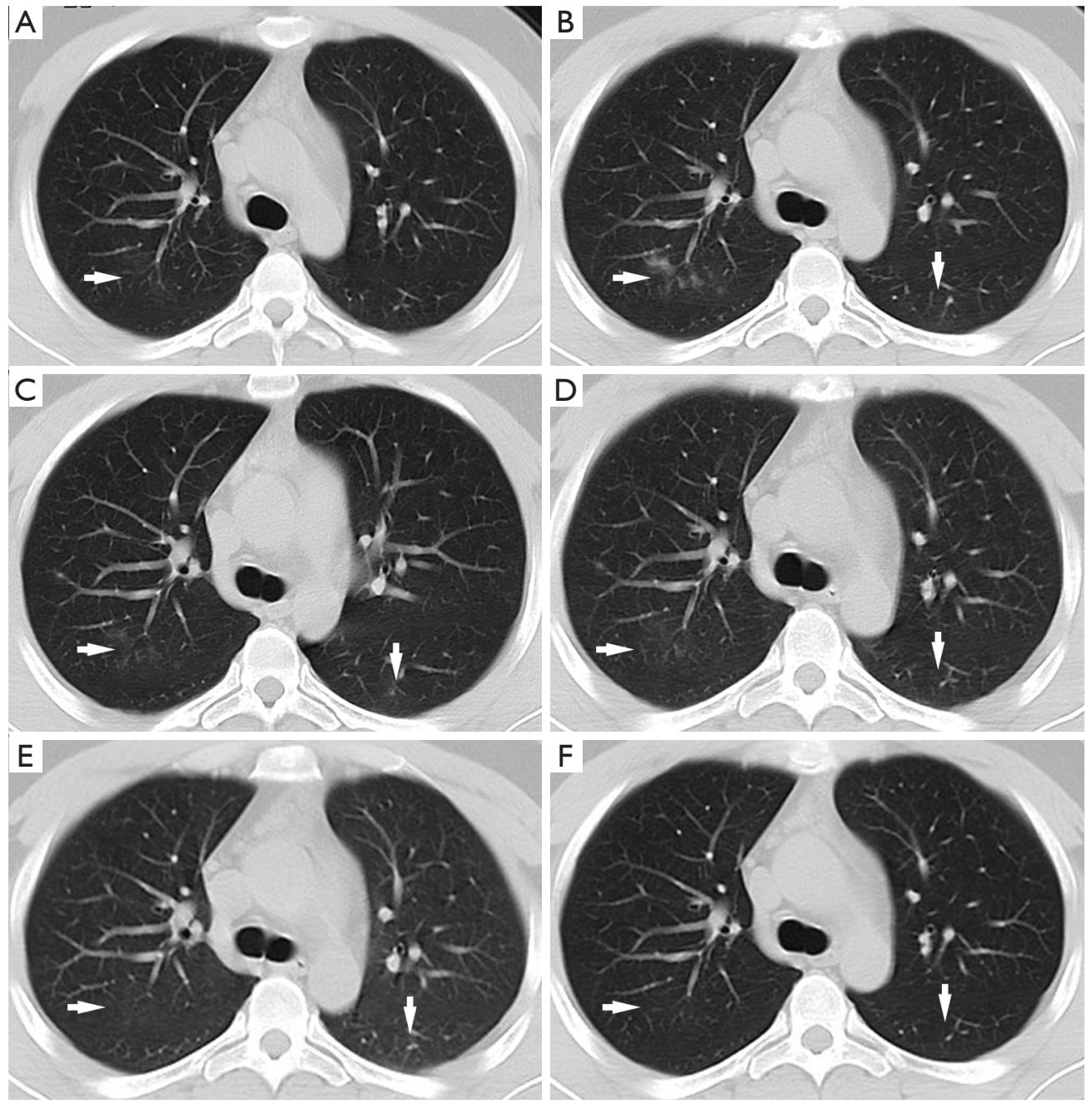

Figure 1 Chest CT images of the 29-year-old patient. (A) The chest CT image taken on day 27 of medical observation shows patchy GGO with halo sign in the upper lobe of the right lung (arrow); (B) follow-up chest CT on day 32 of medical observation shows patchy consolidations in the right upper lobe and patchy GGO in the left lower lobe (arrow); (C) chest CT scans taken on day 3 of the second hospitalization reveals a decreased density of consolidations in the right upper lobe (horizontal arrow) and an increased density of GGO in the left lower lobe (vertical arrow); (D) the follow-up CT on day 6 of the second hospitalization shows that the lesions were partially absorbed (arrow); (E) the third chest CT on day 15 of the second hospitalization shows that the lesions were almost absorbed (arrow); (F) the fourth chest CT on day 21 of the second hospitalization shows that the lesions were absorbed completely (arrow). CT, computed tomography; GGO, ground glass opacity.

on positive result of pathogen test for Staphylococcus aureus, methicillin-resistant Staphylococcus aureus and Hemophilus influenzae. In addition, the SARS-CoV-2 serum antibody tests showed positive result for $\mathrm{IgG}$ and but negative for IgM, suggesting that the patient was at convalescence of SARS-CoV-2 infection. He was then given Moxifloxacin (intravenous, $0.4 \mathrm{~g}$, qd), Ribavirin (intravenous, $0.5 \mathrm{~g}$, bid) and Loratadine (oral, $5 \mathrm{mg}$, qd) treatment, while vital sign monitoring was strengthened. During treatment, no clinical symptoms appeared and the vital signs remained normal. On day 3 of hospitalization, follow-up chest CT revealed decreased density of consolidations in the right upper lobe and increased density of ground glass opacity (GGO) in the left lower lobe (Figure 1C). On day 6 of hospitalization, Moxifloxacin was stopped, and Cefoperazone Sodium/ Sulbactam Sodium (intravenous, $3 \mathrm{~g}$, bid) were administered 
as the pulmonary lesions were not absorbed completely (Figure 1D). On day 15 of hospitalization, negative results of SARS-CoV-2 RNA test were shown for pharyngeal swab and broncho alveolar lavage fluid (BALF) specimens, which were sent to Guizhou Provincial Center for Disease Control and Chinese Center for Disease Control and Prevention (Beijing), and the pulmonary lesions were almost absorbed (Figure 1E), indicating the convalescence of CAP. Therefore, the drug treatment was terminated. On day 21 of hospitalization (May 5, 2020), the fourth chest CT showed that the lesions were absorbed completely (Figure $1 F$ ). Thereafter the patient was discharged.

\section{Discussion}

During the first hospitalization, the patient showed no clinical symptoms or obvious pulmonary lesions. After antiviral therapy, the pharyngeal swab RT-PCR tests showed negative results. The asymptomatic infection may be related to the strong antiviral defense of the host (3). On the other hand, the particular epidemiological history of the patient enabled him to receive RT-PCR test at an early stage, which thus ensured timely treatment after the diagnosis of SARS-CoV-2 infection. In other words, the patient may be at the incubation period of SARS-CoV-2, otherwise the condition would become exacerbated without timely treatment.

After the second admission, the patient was diagnosed with convalescence phase of SARS-CoV-2 infection followed by CAP. To avoid false negative results, BALF and multiple nasopharyngeal swab PCR detections were performed. Secondary bacterial infection is a common complication of viral infection (especially respiratory viruses) (4). Respiratory viral infection can disturb the microbial community balance in patient's upper respiratory tract, resulting in colonization and proliferation of inhaled pathogenic microorganisms in the upper respiratory tract and their subsequent entry into the lower respiratory tract to cause pulmonary infection. Viral infection can also cause dysregulation of macrophages and neutrophils in the alveoli, thereby inhibiting bactericidal activity (5). van den Bergh et al. showed a positive correlation between S. aureus colonization and influenza virus infection (6). Secondary pulmonary infection can lead to a severe clinical course which indicates the necessity of strengthening monitoring of vital signs.

In conclusion, we report a case of asymptomatic SARSCoV-2 infection with secondary CAP. The patient exhibited no clinic symptoms or obvious pulmonary lesions on the first admission, and was discharged after antiviral treatment. However, during medical observation, he developed pneumonia caused by secondary bacterial infection.

\section{Acknowledgments}

Funding: This work was supported by the Guizhou Science and Technology Project \{QKHZC[2020]4Y002\}; and the Guiyang Science and Technology Project \{ZKXM[2020]4-1\}.

\section{Footnote}

Conflicts of Interest: All authors have completed the ICMJE uniform disclosure form (available at http://dx.doi. org/10.21037/qims-20-847). The authors have no conflicts of interest to declare.

Ethical Statement: This report was approved by Jiangjunshan Hospital Institutional Review Board, and the requirement for informed consent was waived.

Open Access Statement: This is an Open Access article distributed in accordance with the Creative Commons Attribution-NonCommercial-NoDerivs 4.0 International License (CC BY-NC-ND 4.0), which permits the noncommercial replication and distribution of the article with the strict proviso that no changes or edits are made and the original work is properly cited (including links to both the formal publication through the relevant DOI and the license). See: https://creativecommons.org/licenses/by-nc-nd/4.0/.

\section{References}

1. Lu CW, Liu XF, Jia ZF. 2019-nCoV transmission through the ocular surface must not be ignored. Lancet 2020;395:e39.

2. He G, Sun W, Fang P, Huang J, Gamber M, Cai J, $\mathrm{Wu} \mathrm{J}$. The clinical feature of silent infections of novel coronavirus infection (COVID-19) in Wenzhou. J Med Virol 2020. [Epub ahead of print]. doi:10.1002/jmv.25861.

3. Fung SY, Yuen KS, Ye ZW, Chan CP, Jin DY. A tug-of-war between severe acute respiratory syndrome coronavirus 2 and host antiviral defence: lessons from other pathogenic viruses. Emerg Microbes Infect 2020;9:558-70.

4. Shen Z, Xiao Y, Kang L, Ma W, Shi L, Zhang L, Zhou Z, Yang J, Zhong J, Yang D, Guo L, Zhang G, Li H, Xu Y, Chen M, Gao Z, Wang J, Ren L, Li M. Genomic diversity 
of severe acute respiratory syndrome-coronavirus 2 in patients with coronavirus disease 2019. Clin Infect Dis 2020;71:713-20.

5. Hanada S, Pirzadeh M, Carver KY, Deng JC. Respiratory viral infection-induced microbiome alterations and secondary bacterial pneumonia. Front Immunol 2018;9:2640.

Cite this article as: Chen J, Tian C, Cheng X, Wang R, Zhou H, Zeng X. A case of asymptomatic SARS-CoV-2 infection followed by secondary community acquired pneumonia. Quant Imaging Med Surg 2020;10(11):22082211. doi: 10.21037/qims-20-847
6. van den Bergh MR, Biesbroek G, Rossen JW, de Steenhuijsen Piters WA, Bosch AA, van Gils EJ, Wang $\mathrm{X}$, Boonacker CW, Veenhoven RH, Bruin JP, Bogaert D, Sanders EA. Associations between pathogens in the upper respiratory tract of young children: interplay between viruses and bacteria. PLoS One 2012;7:e47711. 